\title{
Behavioral and electrophysiological evidence of species-specific face processing
}

\author{
LISA S. SCOTT \\ University of Colorado, Boulder, Colorado \\ and \\ ROBERT W. SHANNON and CHARLES A. NELSON \\ University of Minnesota, Twin Cities, Minneapolis, Minnesota
}

\begin{abstract}
Several recent reports suggest that the behavioral and cortical specificity of face processing may be influenced by experience. To test this hypothesis, behavioral and electrophysiological data were recorded from adults in response to human and monkey faces differing in familiarity and orientation. An analysis of event-related potential and behavioral data revealed differentiation across species, familiarity, and orientation. Behavioral measures were correlated with amplitude and latency measures for each factor of interest. These analyses revealed that accuracy was positively related to the amplitude of the vertex positive potential in the human face task but not in the monkey face task. These findings suggest that previous experience with different categories of faces modulates the link between behavioral and electrophysiological measures of face processing.
\end{abstract}

There is now considerable evidence to suggest that face processing is a unique perceptual ability that may be subserved by its own distinct neural circuitry, most likely located in regions that lie in the inferior temporal cortex (see, e.g., Kanwisher, McDermott, \& Chun, 1997). Support for this view can be found in behavioral, neuropsychological, and neuroimaging data from intact and patient populations (Damasio, Damasio, \& Van Hoesen, 1982; De Renzi, 1986; Farah, 1996) and single-cell and single-unit work with nonhuman primates (Gross, Bender, \& Rocha-Miranda, 1969; Gross, Rocha-Miranda, \& Bender, 1972; Perrett, Mistlin, \& Chitty, 1987; Perrett, Rolls, \& Caan, 1982). What remains unclear is how this circuitry comes to be specialized in the service of face processing.

Although there is broad agreement on the existence of an area in the brain that responds preferentially to faces, there is debate over the mechanism(s) responsible for this preferential activation. Kanwisher et al. (1997) suggested that the ventral temporal cortex contains a limited number of separable areas that are specialized for representing specific categories of stimuli, such as faces or objects,

This work was supported in part by National Institutes of Health Grants NS032976-07 and M01-RR00400 to C.A.N., by Training Grant 5T32 HD07151 from the National Institute of Child Health and Human Development to the Center for Cognitive Sciences at the University of Minnesota, and by the graduate school of the University of Minnesota. The authors thank Elizabeth Nicholson for help with recruiting and testing participants and Jeff Long for statistical consultations. Correspondence concerning this article should be addressed to L. S. Scott, Department of Psychology, University of Colorado, 345 UCB, Boulder, CO 80309 (e-mail:scottls@colorado.edu). and that faces are represented in an area of the ventral temporal cortex called the fusiform face area. Others posit that the fusiform face area may be specific not to faces but rather to any category of stimuli in which expertise has been attained (Gauthier, Behrmann, \& Tarr, 1999; Gauthier, Skudlarski, Gore, \& Anderson, 2000; Gauthier, Tarr, Anderson, Skudlarski, \& Gore, 1999). These reports suggest that the fusiform area is specialized for expert visual recognition of individual exemplars from any object category. Thus, it is still unclear whether the neural and behavioral specificity of face processing represents a domain-specific or a domain-general perceptual ability. Furthermore, an important unresolved question is what role experience with different face categories (e.g., monkey vs. human faces) plays in shaping these face-specific abilities. If, for example, similar perceptual mechanisms are accessed when learning novel human and monkey faces, and if such learning is not dependent on previous experience within each face category, then we should see similar performance, similar generalization, and similar electrophysiological responses to learning both human and monkey faces. However, if experience with certain categories of faces makes it easier to learn subsequent faces within that category, then we would expect to see divergent behavioral and electrophysiological results for human and monkey faces. To examine points of overlap and departure in the various stages of stimulus processing, we recorded event-related potentials (ERPs) while participants viewed human and monkey faces in different orientations.

There are several components of the adult ERP that have been associated with face processing. Both the N170 (Bentin, Allison, Puce, Perez, \& McCarthy, 1996; 
Carmel \& Bentin, 2002) and the vertex positive potential (VPP; Bötzel \& Grüsser, 1989; Jeffreys, 1989, 1996; Jeffreys \& Tukmachi, 1992; Jeffreys, Tukmachi, \& Rockley, 1992) have been linked to the early detection and encoding of faces.

The N170 is a negatively peaked component occurring 120-200 msec after stimulus onset and is prominent over posterior lateral leads. The response of the N170 is typically not different for familiar versus unfamiliar faces (Bentin \& Deouell, 2000; Eimer, 2000), is enhanced and delayed by stimulus inversion (Rossion et al., 1999; Rossion et al., 2000; Sagiv \& Bentin, 2001), and can be elicited by schematic drawings (Carmel \& Bentin, 2002; Sagiv \& Bentin, 2001) and isolated facial features, such as the eyes (Bentin et al., 1996). The VPP occurs at approximately the same latency as the N170 (150-200 msec after stimulus onset) and is maximal at midline central and parietal (Jeffreys, 1989) as well as frontocentral (Bötzel \& Grüsser, 1989; Rossion, Joyce, Cottrell, \& Tarr, 2003) sites. Like the N170, the VPP tends to be larger and respond earlier to faces and face-like stimuli in comparison with objects (Jeffreys, 1996; Jeffreys \& Tukmachi, 1992) and is not affected by changes in the size of the stimulus (Jeffreys, 1989). However, inverting the face, using a contrast-polarity reversed image, or removing features tends to increase the latency response (Jeffreys, 1989). Recent research into these two components in relation to each other suggests that they represent opposite ends of a dipole ${ }^{1}$ arising from the same neural source(s) (Joyce \& Rossion, 2005; Rossion et al., 2003). Furthermore, depending on the type of reference used (e.g., mastoid vs. average), the N170 tends to be attenuated and sometimes nonexistent. Thus, when using a mastoid reference, it is recommended that one examine the VPP as opposed to the N170 (Joyce \& Rossion, 2005).

Differences in processing human versus nonhuman primate faces have previously been investigated using ERPs. Carmel and Bentin (2002) found a longer N170 latency in response to ape in comparison with human faces. Similarly, de Haan, Pascalis, and Johnson (2002) also looked at the effects of viewing monkey versus human upright and inverted faces on the adult N170 and found that inversion increased the amplitude and latency of the N170 for human but not for monkey faces. These results suggest experience-based differences in the processing of stimuli, supporting the notion that cortical specificity in face processing may indeed be due to the extensive experience humans have in processing human faces. However, in these experiments the differences between learning novel human faces and learning novel monkey faces were not examined, and no attempt was made to link behavioral and electrophysiological indices of processing these different types of stimuli.

A third ERP component of interest in face processing is what some have called the N300 (Barrett, Rugg, \& Perrett, 1988; Bentin \& Deouell, 2000; Eimer, 2000). This component has been found to differentiate familiar and unfamiliar stimuli. More specifically, familiar faces (such as those of celebrities or politicians) typically elicit a greater response in comparison with unfamiliar faces. However, it is not clear how newly learned or familiar faces affect the specificity of this component.

Although several differences between human and monkey face processing have been identified in previous investigations using ERPs, some questions are still left unanswered. First, how does learning novel monkey faces differ from learning novel human faces? Second, how does learning a face in one orientation generalize to the same face when seen in a different orientation, and does this phenomenon differ across species? Finally, how do behavioral recognition abilities (indexed by measures of reaction time [RT] and accuracy) relate to ERP differences across species? To answer these questions, adult participants studied pictures of frontally oriented monkeys and humans and then viewed and responded to a series of faces, including (1) the frontally oriented familiar faces, (2) pictures of the familiar face in different orientations (e.g., turned to the side), (3) unfamiliar faces in the frontal orientation, and (4) the same unfamiliar faces in a different orientation (see Figure 1).

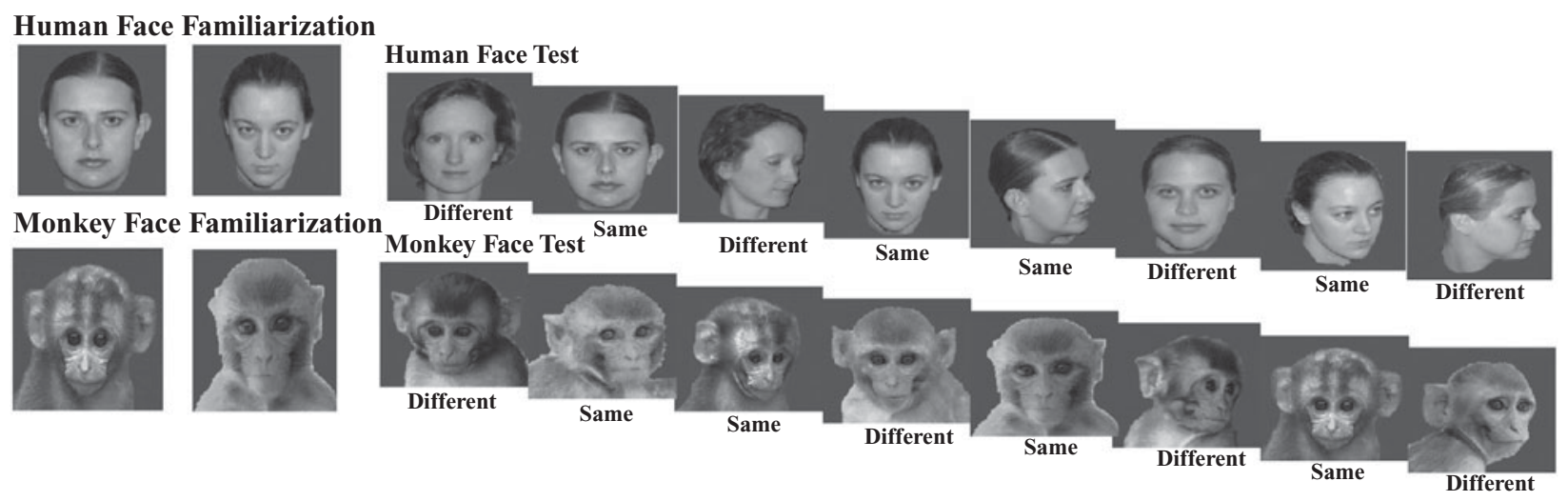

Figure 1. Stimuli presented on the computer screen to participants for the discrimination task. Familiar pictures (left) are enlarged for clarity, followed by test pictures (right) in random configuration. 


\section{METHOD}

\section{Participants}

The participants were 14 healthy, right-handed adults recruited from an undergraduate population at the University of Minnesota. An additional 15 participants were excluded because of belowchance performance on the monkey face task $(n=5)$ and excessive eye or movement artifacts on the monkey face task, the human face task, or both $(n=10)$. The University of Minnesota Institutional Review Board approved all procedures used in this study. All participants gave informed consent to participate.

\section{Stimuli}

The stimuli included grayscale images of monkey and human faces (see Figure 1). Each category of faces consisted of four individuals. Two images (frontal, profile) of each individual face were used. A separate pilot study $(n=8)$ was conducted to test for discriminability differences between human and monkey faces using a side-by-side matching task. $d^{\prime}$ for human faces was $3.04(S D=0.686$; range, $1.55-3.62)$, and $d^{\prime}$ for monkey faces was $2.71(S D=1.23$; range, $1.24-4.50)$. These means were not significantly different from each other $[t(7)=-0.964, p=.367]$. Measures of RT and accuracy were also not significantly different for human and monkey face stimuli.

\section{Procedure}

Each participant completed separate human and monkey face tasks while ERPs were recorded from the scalp. Each task consisted of a familiarization period and test trials. For each task, the participants were instructed to look at two pictures of frontally oriented monkeys for as long as it took to memorize these faces (which they indicated by buttonpress). They then viewed a series of faces, including (1) both of the frontally oriented familiar faces, (2) the familiar faces in different orientations (e.g., turned to the side), (3) two unfamiliar faces in the frontal orientation, and (4) the same two unfamiliar faces in a different orientation (see Figure 1). The participants were asked to press one button if the face they were currently looking at was the same as one of the familiar faces and another button if the face was different from the familiar faces (regardless of orientation). The participants completed this task for both monkey and human faces; the order of the tasks was counterbalanced across participants. Each task consisted of 160 trials, or 40 presentations of each of the four conditions presented at random.

ERPs were recorded from 29 tin scalp electrodes, which were sewn into a Lycra cap (Electro-Cap International, Eaton, OH). Two separate tin electrodes were placed on the mastoid bones behind the ears and held in place with sticky foam. The electrooculogram (EOG) was recorded from electrodes placed above and below the right eye. Impedances were accepted if they were less than $5 \mathrm{k} \Omega$. On the basis of interelectrode distance, all electrodes were referenced to the scalp electrode $\mathrm{Cz}$ (located at the vertex) and then rerefer- enced offline to mathematically linked mastoids. EEG data were acquired with a Grass Neurodata Acquisition System with Model $12 \mathrm{~A} 5$ amplifiers. The gain was set to 50,000 for all scalp leads. The gain for EOG was set at 5,000. A band-pass filter from 0.1 to $30 \mathrm{~Hz}$ and a $60-\mathrm{Hz}$ notch filter were in place. EEG data were sampled at $200 \mathrm{~Hz}$.

After the data were collected, they were edited, averaged, and analyzed using ERPW, an ERP editing and averaging program developed for use in our laboratory. The data were edited for artifacts using a regression algorithm in this program (Gratton, Coles, \& Donchin, 1983). Individual trials were excluded from the analysis if they included more than three channels with excessive artifacts arising from body or eye movements. Trials were rejected if EEG responses exceeded $\pm 100 \mu \mathrm{V}$, if the EOG showed changes of greater than $100 \mu \mathrm{V}$ within a $50-\mathrm{msec}$ window, or if artifacts were detected in any of the reference channels (A1, A2, or Cz).

Individual artifact-free trials were combined to form average waveforms for each participant and each condition. Only trials in which correct responses were made were included in the individual averages. Grand averages were computed for each condition as well as collapsing the data across conditions (i.e., all monkey trials and all human trials), to examine possible main effects.

\section{RESULTS}

\section{Behavior}

Measures of accuracy were submitted to a 2 (species: human vs. monkey) $\times 2$ (familiarity: familiar vs. unfamiliar) $\times 2$ (orientation: frontal vs. profile) MANOVA. Overall analyses of the results suggest that there was increased accuracy $[F(1,13)=35.32, p<.001]$ for human versus monkey faces (Figure 2 ). In addition, the participants exhibited improved accuracy to familiar faces in the frontal orientation $[F(1,13)=18.23, p<.001]$. This effect is apparent in both the monkey and the human face tasks, with marked differences in the monkey face task. In the human but not the monkey face task, these effects tend to generalize to the profile orientation $[F(1,13)=$ $7.45, p<.05]$. RTs to human faces $(M=726.2 \mathrm{msec}$, $S D=162.3)$ were significantly shorter than RTs to monkey faces $(M=943.3 \mathrm{msec}, S D=170.2$, all $p \mathrm{~s}<.05)$.

\section{Event-Related Potentials}

The primary goal of the present study was to further elucidate the response patterns of the VPP and the N300 across human and monkey face processing. However, the

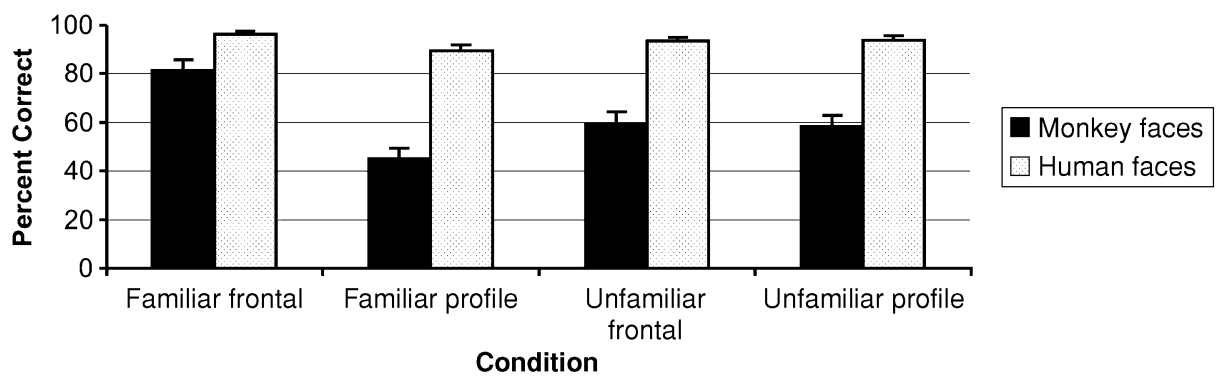

Figure 2. Behavioral measures of accuracy to human and monkey faces across the familiar frontal, familiar profile, unfamiliar frontal, and unfamiliar profile conditions. 
Table 1

Mean Significant Main Effects (and Standard Errors) for the N100, VPP, and N300 Components

\begin{tabular}{|c|c|c|c|c|c|c|c|c|c|c|c|c|}
\hline \multirow[b]{3}{*}{ Component } & \multicolumn{4}{|c|}{ Species } & \multicolumn{4}{|c|}{ Familiarity } & \multicolumn{4}{|c|}{ Orientation } \\
\hline & \multicolumn{2}{|c|}{ Monkey } & \multicolumn{2}{|c|}{ Human } & \multicolumn{2}{|c|}{ Familiar } & \multicolumn{2}{|c|}{ Unfamiliar } & \multicolumn{2}{|c|}{ Frontal } & \multicolumn{2}{|c|}{ Profile } \\
\hline & $M$ & $S E$ & $M$ & $S E$ & $M$ & $S E$ & $M$ & $S E$ & $M$ & $S E$ & $M$ & $S E$ \\
\hline N100 & & & & & & & & & & & & \\
\hline $\begin{array}{l}\text { Regional } \\
\text { amplitude }\end{array}$ & & & & & & & & & & & & \\
\hline $\begin{array}{c}\text { differences } \\
\text { Hemisphere } \\
\text { amplitude }\end{array}$ & $-5.52^{* *}$ & 0.55 & $-4.32^{* *}$ & 0.38 & -4.81 & 0.47 & -5.04 & 0.44 & -5.03 & 0.45 & -4.82 & 0.46 \\
\hline $\begin{array}{l}\text { differences } \\
\text { Regional }\end{array}$ & $-5.05^{* *}$ & 0.73 & $-3.19^{* *}$ & 0.58 & -3.87 & 0.72 & -4.35 & 0.52 & -4.23 & 0.64 & -4.01 & 0.59 \\
\hline $\begin{array}{l}\text { latency } \\
\text { differences }\end{array}$ & $119.03^{* *}$ & 3.82 & $106.42^{* *}$ & 3.44 & $110.74^{*}$ & 3.71 & $114.71^{*}$ & 3.13 & 112.63 & 3.21 & 112.82 & 3.82 \\
\hline $\begin{array}{l}\text { Hemisphere } \\
\text { latency } \\
\text { differences }\end{array}$ & $116.79^{*}$ & 5.44 & $102.36^{*}$ & 5.12 & 106.52 & 4.83 & 111.62 & 4.72 & 109.79 & 4.77 & 108.36 & 4.93 \\
\hline VPP & & & & & & & & & & & & \\
\hline $\begin{array}{l}\text { Regional } \\
\text { amplitude } \\
\text { differences }\end{array}$ & $6.88^{* *}$ & 0.72 & $5.75^{* *}$ & 0.88 & 6.30 & 0.82 & 6.33 & 0.76 & 6.38 & 0.76 & 6.25 & 0.83 \\
\hline $\begin{array}{l}\text { Hemisphere } \\
\text { amplitude } \\
\text { differences }\end{array}$ & 6.30 & 0.98 & 6.16 & 1.11 & 6.27 & 1.06 & 6.19 & 1.02 & 6.38 & 0.97 & 6.10 & 1.12 \\
\hline $\begin{array}{l}\text { Regional } \\
\text { latency } \\
\text { differences }\end{array}$ & $187.21^{* *}$ & 2.17 & $172.90^{* *}$ & 2.85 & $178.62^{*}$ & 2.50 & $181.44^{*}$ & 1.96 & $178.45^{*}$ & 2.47 & $181.61^{*}$ & 1.95 \\
\hline $\begin{array}{l}\text { Hemisphere } \\
\text { latency } \\
\text { differences }\end{array}$ & $183.91^{* *}$ & 2.86 & $172.53^{* *}$ & 3.68 & 176.96 & 3.40 & 179.48 & 2.78 & $175.26^{* *}$ & 3.37 & $181.18^{* *}$ & 2.75 \\
\hline $\begin{array}{l}\text { N300 } \\
\text { Regional } \\
\text { amplitude } \\
\text { differences }\end{array}$ & 0.25 & 0.60 & -0.15 & 0.78 & $0.54^{*}$ & 0.66 & $-0.43^{*}$ & 0.63 & 0.27 & 0.64 & -0.16 & 0.63 \\
\hline $\begin{array}{l}\text { Hemisphere } \\
\text { average } \\
\text { amplitude } \\
\text { differences }\end{array}$ & 0.31 & 0.62 & -0.01 & 0.81 & $0.59^{* *}$ & 0.68 & $-0.38^{* *}$ & 0.66 & 0.33 & 0.67 & -0.11 & 0.65 \\
\hline
\end{tabular}

N100 component was also identified as exhibiting condition differences, and thus analyses were conducted across all three components. For each component, the data were submitted to either a $2 \times 2 \times 2 \times 2$ or a $2 \times$ $2 \times 2 \times 3$ MANOVA to determine differences across conditions and regions of the scalp. The MANOVAs consisted of two levels of species (human and monkey), two levels of familiarity (familiar and unfamiliar), two levels of orientation (frontal and profile), and either two levels of hemisphere (left and right) or three levels of region (frontal, central, and parietal). Follow-up analyses of significant main effects and interactions were conducted using paired comparisons corrected for multiple comparisons (using the Bonferroni method). For clarity, only significant findings are reported.

N100. For the N100 component, maximum negative amplitude and the corresponding latency were measured within a window that best captured this component (60-160 msec after stimulus onset). For the N100, the response to the monkey faces was greater in amplitude $[F(1,13)=12.84, p<.01]$ and longer in latency $[F(1,13)=6.72, p<.01]$ than the response to the human faces for both the regional comparisons (see Figure 3A) and the hemispheric comparisons [amplitude, $F(1,13)=$ $13.67, p<.01$; latency, $F(1,13)=7.50, p<.05]$. In addition, N100 latency in response to unfamiliar faces was significantly longer in comparison with that in response to familiar faces $[F(1,13)=6.72, p<.05]$. The response over the frontal region reflected a greater amplitude $[F(2,12)=4.46, p<.05]$ and a longer latency N100 peak $[F(2,12)=7.27, p<.01]$ in comparison with the responses over the central and parietal regions. Finally, the peak of the N100 in the right hemisphere was significantly later than the peak in the left hemisphere $[F(1,13)=7.92$, $p<.05]$. See Table 1 for means and standard errors of these effects.

N100 and behavior. Behavioral measures of accuracy and RT across conditions did not predict the amplitude or latency of the N100 (all $p$ s $>.10$ ).

VPP. As was described earlier, a recent report suggests that the VPP, a positively peaked component, is the dipolar opposite of the N170 face component (Joyce \& Rossion, 2005; Rossion et al., 2003). This work implies that the N170 and the VPP stem from the same neural 
Table 1 (Continued)

Mean Significant Main Effects (and Standard Errors) for the N100, VPP, and N300 Components

\begin{tabular}{|c|c|c|c|c|c|c|c|c|c|}
\hline \multicolumn{4}{|c|}{ Hemisphere } & \multicolumn{6}{|c|}{ Region } \\
\hline \multicolumn{2}{|c|}{ Left } & \multicolumn{2}{|c|}{ Right } & \multicolumn{2}{|c|}{ Frontal } & \multicolumn{2}{|c|}{ Central } & \multicolumn{2}{|c|}{ Parietal } \\
\hline$M$ & $S E$ & $M$ & $S E$ & $M$ & $S E$ & $M$ & $S E$ & $M$ & $S E$ \\
\hline n.a. & n.a. & n.a. & n.a. & $-5.75^{*}$ & 0.62 & -4.90 & 0.52 & $-4.12^{*}$ & 0.61 \\
\hline-3.91 & 0.60 & -4.33 & 0.64 & n.a. & n.a. & n.a. & n.a. & n.a. & n.a. \\
\hline n.a. & n.a. & n.a. & n.a. & $115.95^{* *}$ & 3.78 & 113.15 & 3.51 & $109.07^{* *}$ & 4.47 \\
\hline 106.59 & 4.59 & 111.56 & 4.52 & n.a. & n.a. & n.a. & n.a. & n.a. & n.a. \\
\hline n.a. & n.a. & n.a. & n.a. & 6.00 & 1.00 & 6.01 & 1.01 & 6.95 & 0.89 \\
\hline 6.16 & 1.13 & 6.30 & 0.95 & n.a. & n.a. & n.a. & n.a. & n.a. & n.a. \\
\hline n.a. & n.a. & n.a. & n.a. & 176.97 & 3.05 & 178.60 & 3.18 & 184.54 & 2.60 \\
\hline 177.85 & 3.03 & 178.60 & 3.13 & n.a. & n.a. & n.a. & n.a. & n.a. & n.a. \\
\hline n.a. & n.a. & n.a. & n.a. & $1.03^{* *}$ & 0.60 & $-0.92^{* *}$ & 0.73 & n.a. & n.a. \\
\hline-0.20 & 0.61 & 0.42 & 0.72 & n.a. & n.a. & n.a. & n.a. & n.a. & n.a. \\
\hline
\end{tabular}

generator(s) and have the same sensitivity to changes across conditions. This component is typically temporally coincident with the N170 component and is thought to be one of the earliest ERP markers of face and object processing (Bentin et al., 1996; Jeffreys, 1989, 1996; Jeffreys et al., 1992; Rossion et al., 2000). On the basis of the number of electrodes used, the interelectrode distances, and the locations of the electrodes (Bertrand, Perrin, \& Pernier, 1985; Dien, 1998; see Picton et al., 2000), we referenced all scalp electrodes online to the vertex and then rereferenced them to mathematically linked mastoids. ${ }^{2}$ When this type of referencing is utilized, the N170 component tends to diminish in amplitude, and any condition differences are better seen at the VPP (Joyce \& Rossion, 2005).

For the VPP, maximum positive amplitude and the corresponding latency were measured within a window that best captured this component (140-210 msec after stimulus onset). As is illustrated in Table 1 and Figure 3B, the amplitude of the VPP was significantly greater in response to the monkey faces in comparison with the human faces $[F(1,13)=9.79, p<.01]$. The latency response was longer to the monkey than to the human $[F(1,13)=$ 28.03, $p<.001]$, to the unfamiliar than to the familiar $[F(1,13)=7.17, p<.05]$, and to the profile than to the frontally oriented $[F(1,13)=4.59, p<.05]$ faces (see Table 1 and Figure 4). Monkey faces also elicited a greater amplitude response in the parietal region $[F(2,12)=$ $12.50, p<.001]$ in comparison with the frontal and central regions. These differences are not apparent across regions in the human conditions (see Table 2). Furthermore, there was a greater VPP amplitude to familiar monkey faces in comparison with familiar human faces in the parietal region $[F(2,12)=6.124, p<.01$; see Table 3].

Comparisons of the VPPs revealed no significant amplitude differences across hemispheres. Similar to what is reported above, amplitude main effects of species and orientation were found for hemispheric analyses. A significant species $\times$ familiarity $\times$ hemisphere $[F(1,13)=$ $6.05, p<.05]$ interaction was found for latency measures. This interaction is driven by longer VPP latency to 

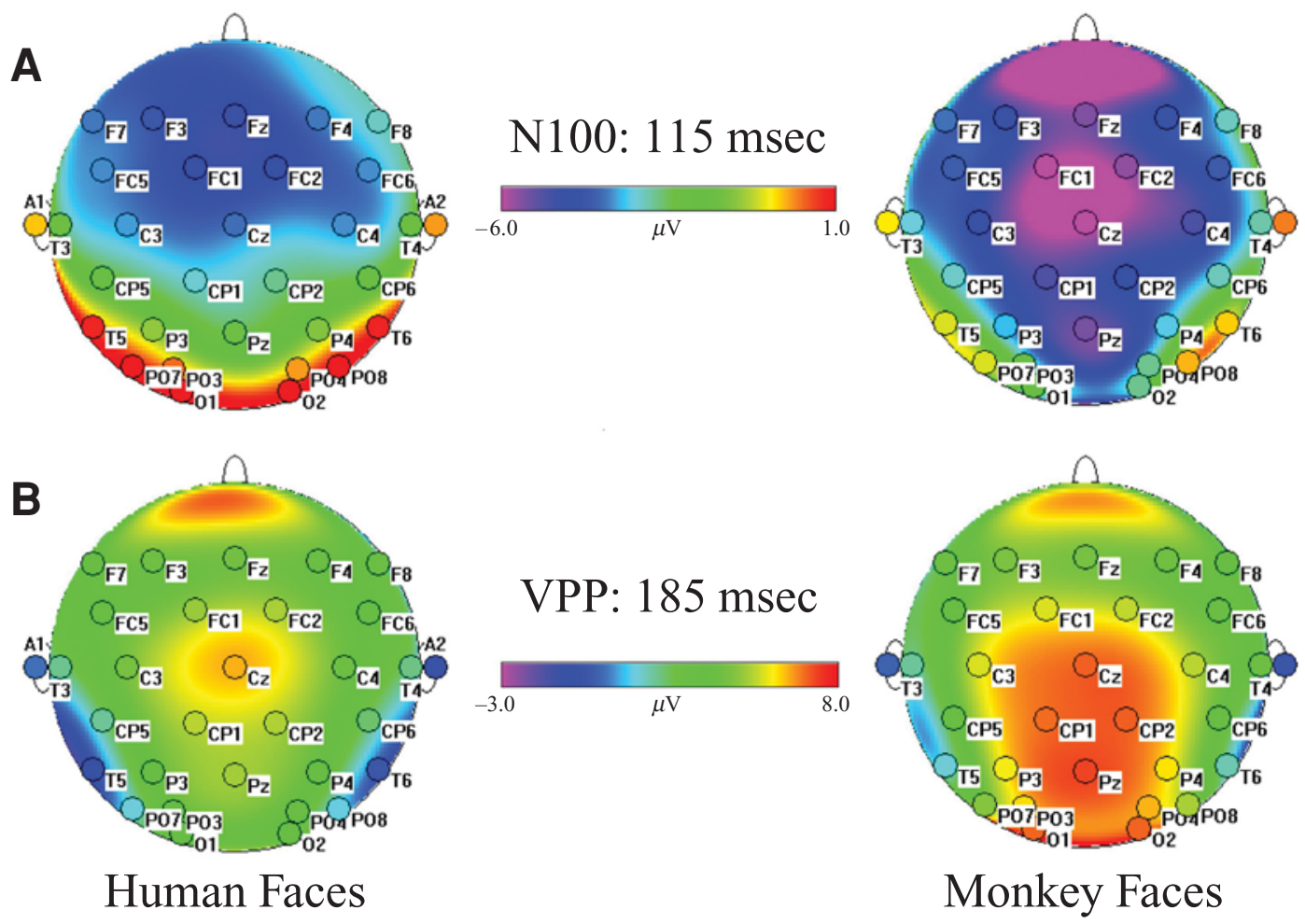

Figure 3. Topographic head plots using a spherical spline interpolation of the ERP response to the human (left) and monkey (right) faces for (A) the N100 and (B) the VPP.

unfamiliar in comparison with familiar monkey faces in the left hemisphere and by a longer latency in the right in comparison with the left hemisphere for familiar monkey faces (see Table 3).

VPP and behavior. Regression analyses were conducted to determine whether or not behavioral measures of accuracy and RT predicted the amplitude or latency of the VPP over the central region (where the largest VPP was found across all conditions). To equate for possible differences in task difficulty, only ERP trials in which correct responses were made were included in these analyses. Results indicate that accuracy in the human face task is positively related to the amplitude of the VPP $\left[F(1,13)=4.92, R^{2}=.32, p<.05\right]$. This effect was not found in the monkey face task (see Figure $5 \mathrm{~A}$ ). To determine whether this effect was related to the overall poorer performance on the monkey face task in comparison with the human face task, an additional analysis was conducted using accuracy and VPP amplitude to the familiar frontal human and monkey faces only. Although accuracy to the familiar frontal monkey faces was still significantly worse than that to the familiar frontal human faces (see Figure 2), accuracy to both was well above a standard deviation of chance. Results of this analysis mirror those of the previous analysis: The accuracy to familiar frontal human faces predicts the amplitude of the VPP response in that higher accuracy is positively related to the amplitude of the $\operatorname{VPP}\left[F(1,13)=8.40, R^{2}=\right.$ $.41, p<.01]$. This correlation was not found for the fa- miliar frontal monkey faces (see Figure 5B). There was no relation between the latency of the VPP and either RT or accuracy.

N300. For the N300 component, the average amplitude response within 220-340 msec after stimulus onset was measured from the left and right hemispheres and from central and frontal regions (the parietal region was not included in these analyses because there was not a prominent N300 component in this region). For both comparisons, the unfamiliar faces elicited a greater ERP response than did the familiar faces [left vs. right, $F(1,13)=6.28$, $p<.05$; central vs. frontal, $F(1,13)=6.96, p<.05$; see Figure 6, Table 1]. In addition, the frontal N300 was significantly larger than the central N300 $[F(1,13)=16.50$, $p<.001]$.

The response of this component was greater over the frontal region in comparison with the central region $[F(1,13)=7.24, p<.05]$ for both frontal and profile orientations $(p s<.05)$. There was also greater amplitude response to unfamiliar than to familiar faces in the right hemisphere $[F(1,13)=19.25, p<.01$; see Table 2].

N300 and behavior. Behavioral measures of accuracy and RT across conditions did not predict the amplitude or latency of the N300 (all $p$ s $>.10$ ).

\section{DISCUSSION}

The results of the present study have important implications for the understanding of face processing. The be- 


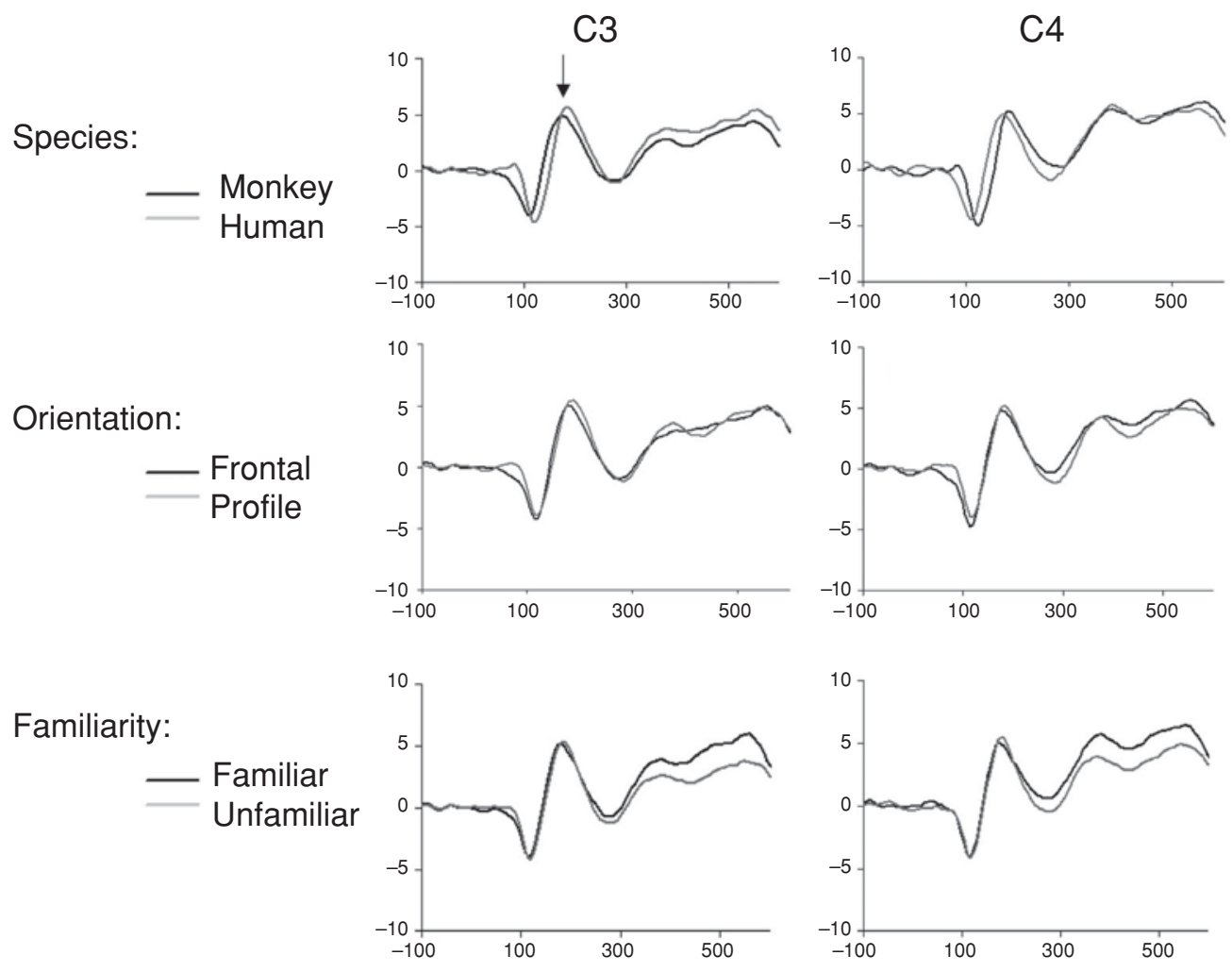

Figure 4. Latency differences for the VPP. ERP grand average of the response to the (top) monkey (black line) and human (gray line) faces, (middle) frontally oriented (black line) and profile (gray line) faces, and (bottom) familiar (black line) and unfamiliar (gray line) faces at C3 (left) and C4 (right). The waveform was shifted so that baseline (activity from -100 to 0 ) was equivalent across different conditions and electrodes.

havioral results indicate that adults learn and subsequently recognize human faces more readily than monkey faces. More specifically, the participants were good at recognizing both human and monkey familiar (frontal) faces, although they were slightly better at recognizing human faces. This ability seemed to generalize to the same familiar human profile faces, and the participants were also very good at recognizing unfamiliar human frontal and profile faces. However, performance declined and RT increased in the monkey face task. The participants did not appear to generalize from the frontal orientation to the profile orientation for the familiar faces. Furthermore, unfamiliar monkey faces posed a problem regardless of orientation. These results suggest that the participants were able to generalize identity across changes in orientation for human but not for monkey faces.

Although electrophysiological results did not mirror the behavioral results (i.e., there was no evidence of differential generalization across orientations for human and monkey faces), there was evidence of differential processing of monkey and human faces. Electrophysiological results reveal differences between human and monkey faces for the N100 and VPP, familiarity and orientation differences for the VPP, and familiarity effects for the N300.
The N100 is typically associated with direction of attention or attentional processes (Hillyard, 1981). In the present study, the N100 is larger in amplitude and longer in latency in response to monkey faces in comparison with human faces. These results are consistent with previous research indicating a larger N100 in response to stimuli that require more attention. On the basis of the behavioral results of the present study, the monkey face task tended to be more demanding than the human face task, possibly indicating that more attentional resources were devoted to this task in comparison with the human face-processing task. However, unlike the amplitude and latency for the VPP component, neither measure for the N100 component was correlated with measures of accuracy or RT.

On the basis of previous research, we expected the effects of the VPP to be similar to what has typically been found in studies of the N170 as well as previous studies of the VPP. We found that the VPP component was manipulated by changes in species, orientation, and familiarity. In accordance with previous studies of the specificity of the N170, we found that the monkey faces elicited greater amplitude response and longer latency than did the human faces. The VPP component appears to be much more diffuse in response to monkey faces in comparison with human faces (see Figure 4B), suggesting greater cortical 
Table 2

Mean Significant Two-Way Interactions (and Standard Errors) for the N100, VPP, and N300 Components

\begin{tabular}{|c|c|c|c|c|c|}
\hline Component & Interaction & Condition 1 & Condition 2 & $M$ & $\overline{S E}$ \\
\hline \multicolumn{6}{|l|}{ VPP } \\
\hline \multirow[t]{4}{*}{ Latency for hemisphere differences } & \multirow[t]{4}{*}{ species $\times$ hemisphere* } & \multirow[t]{2}{*}{ monkey } & left & 182.41 & 2.82 \\
\hline & & & right & 185.41 & 3.03 \\
\hline & & \multirow[t]{2}{*}{ human } & left & 173.30 & 3.82 \\
\hline & & & right & 171.76 & 3.77 \\
\hline \multirow[t]{6}{*}{ Maximum amplitude for regional differences } & \multirow[t]{6}{*}{ species $\times$ region ${ }^{* *}$} & \multirow[t]{3}{*}{ monkey } & frontal & 5.88 & 0.97 \\
\hline & & & central & 6.26 & 0.97 \\
\hline & & & parietal & 8.50 & 0.97 \\
\hline & & \multirow[t]{3}{*}{ human } & frontal & 6.15 & 1.10 \\
\hline & & & central & 5.70 & 1.07 \\
\hline & & & parietal & 5.42 & 0.91 \\
\hline \multirow[t]{12}{*}{ Latency for regional differences } & \multirow[t]{6}{*}{ species $\times$ region* } & \multirow[t]{3}{*}{ monkey } & frontal & 183.34 & 3.01 \\
\hline & & & central & 182.98 & 2.90 \\
\hline & & & parietal & 195.29 & 2.14 \\
\hline & & \multirow[t]{3}{*}{ human } & frontal & 173.82 & 3.86 \\
\hline & & & central & 170.96 & 3.72 \\
\hline & & & parietal & 173.80 & 4.14 \\
\hline & \multirow[t]{6}{*}{ orientation $\times$ region $*$} & \multirow[t]{3}{*}{ frontal } & frontal & 174.32 & 3.41 \\
\hline & & & central & 174.81 & 3.59 \\
\hline & & & parietal & 185.24 & 2.90 \\
\hline & & \multirow[t]{3}{*}{ profile } & frontal & 181.87 & 3.03 \\
\hline & & & central & 179.12 & 2.69 \\
\hline & & & parietal & 183.85 & 2.64 \\
\hline \multicolumn{6}{|l|}{ N300 } \\
\hline \multirow[t]{8}{*}{ Average amplitude for hemisphere differences } & \multirow[t]{4}{*}{ species $\times$ orientation* } & \multirow[t]{2}{*}{ monkey } & frontal & -0.01 & 0.70 \\
\hline & & & profile & 0.64 & 0.62 \\
\hline & & \multirow[t]{2}{*}{ human } & frontal & 0.67 & 0.76 \\
\hline & & & profile & -0.87 & 0.93 \\
\hline & \multirow[t]{4}{*}{ familiarity $\times$ hemisphere ${ }^{* *}$} & \multirow[t]{2}{*}{ familiar } & left & 0.08 & 0.60 \\
\hline & & & right & 1.12 & 0.81 \\
\hline & & \multirow[t]{2}{*}{ unfamiliar } & left & -0.48 & 0.70 \\
\hline & & & right & -0.27 & 0.70 \\
\hline \multirow[t]{4}{*}{ Average amplitude for regional differences } & \multirow[t]{4}{*}{ species $\times$ orientation* } & \multirow[t]{2}{*}{ monkey } & frontal & -0.05 & 0.66 \\
\hline & & & profile & 0.57 & 0.60 \\
\hline & & \multirow[t]{2}{*}{ human } & frontal & 0.60 & 0.74 \\
\hline & & & profile & -0.90 & 0.90 \\
\hline
\end{tabular}

specificity in response to human faces than monkey faces. In addition, slightly changing the orientation of faces induced latency differences (longer latency to profile faces) similar to those seen when faces are inverted for both the N170 (Rossion et al., 1999; Rossion et al., 2000; Sagiv \& Bentin, 2001) and the VPP (Jeffreys, 1989). These results are consistent with what de Haan et al. (2002) report for the N170 in adults; however, we did not find any amplitude differences across changes in orientation. Interestingly, measures of accuracy on this task predicted the amplitude of the VPP component in the human but not the monkey face task. Even when performance was well above a standard deviation of chance (for the familiar frontal monkey condition), the accuracy in the human face task significantly predicted the amplitude of the VPP, whereas there was no relation between accuracy and amplitude in the monkey face condition. Thus, as accuracy increases in the human face task, the amplitude of the VPP also increases. These results are noteworthy for two reasons. First, they link behavioral measures with a specific ERP component - the VPP-further supporting the connection between this component and face processing. Second, these data sug- gest that learning novel human faces benefits from the extensive experience adults have viewing human faces. However, experience with human faces does not influence the ability to learn monkey faces, despite the similar structures of human and monkey faces. This result supports the notion that the specialization of face processing in humans is specific to the categories of faces that one has experience processing. This relation between experience and VPP amplitude is consistent with a similar correlation between behavior measures of car expertise and the N170 (Gauthier, Curran, Curby, \& Collins, 2003).

However, it is unclear at this point whether or not the relation between accuracy and amplitude is due to expertise; it is possible that these results are confounded by the difficulty of the task, although the lack of significant correlations between behavior and amplitude or latency for the N100 or the N300 suggests that these effects cannot be accounted for simply by task difficulty. This result is, however, consistent with reports that the N170 is larger in amplitude for inverted faces in comparison with upright faces (de Haan et al., 2002) and with a recent report suggesting that the N170 is larger 
Table 3

Mean Significant Three-Way Interactions (and Standard Errors) for the N100, VPP, and N300 Components

\begin{tabular}{|c|c|c|c|c|c|c|}
\hline Component & Interaction & Condition 1 & Condition 2 & Condition 3 & $M$ & $S E$ \\
\hline \multicolumn{7}{|l|}{ VPP } \\
\hline \multirow{12}{*}{$\begin{array}{l}\text { Maximum amplitude for } \\
\text { regional differences }\end{array}$} & & & & & & \\
\hline & species $\times$ familiarity $\times$ region* & monkey & familiar & $\begin{array}{l}\text { frontal } \\
\text { central }\end{array}$ & $\begin{array}{l}5.96 \\
6.39\end{array}$ & $\begin{array}{l}1.00 \\
1.00\end{array}$ \\
\hline & & & & parietal & 8.05 & 1.01 \\
\hline & & & unfamiliar & frontal & 5.74 & 1.10 \\
\hline & & & & central & 6.09 & 1.10 \\
\hline & & & & parietal & 8.93 & 1.00 \\
\hline & & human & familiar & frontal & 6.09 & 1.10 \\
\hline & & & & central & 5.74 & 1.10 \\
\hline & & & & parietal & 5.60 & 0.97 \\
\hline & & & unfamiliar & frontal & 6.21 & 1.16 \\
\hline & & & & central & 5.67 & 1.10 \\
\hline & & & & parietal & 5.24 & 0.90 \\
\hline \multirow{9}{*}{$\begin{array}{l}\text { Latency for hemisphere } \\
\text { differences }\end{array}$} & & & & & & \\
\hline & species $\times$ familiarity $\times$ hemisphere* & monkey & familiar & left & 179.76 & 3.27 \\
\hline & & & & right & 184.47 & 3.54 \\
\hline & & & unfamiliar & left & 185.07 & 2.51 \\
\hline & & & & right & 186.35 & 2.72 \\
\hline & & human & familiar & left & 173.05 & 3.98 \\
\hline & & & & right & 170.55 & 3.93 \\
\hline & & & unfamiliar & left & 173.55 & 3.94 \\
\hline & & & & right & 172.97 & 3.73 \\
\hline \multicolumn{7}{|l|}{ N300 } \\
\hline \multirow{9}{*}{$\begin{array}{l}\text { Average amplitude for } \\
\text { hemisphere differences }\end{array}$} & & & & & & \\
\hline & species $\times$ orientation $\times$ hemisphere ${ }^{* *}$ & monkey & frontal & left & -0.17 & 0.71 \\
\hline & & & & right & 0.14 & 0.78 \\
\hline & & & profile & left & -0.18 & 0.62 \\
\hline & & & & right & 1.46 & 0.69 \\
\hline & & human & frontal & left & -0.43 & 0.64 \\
\hline & & & & right & 1.78 & 1.02 \\
\hline & & & profile & left & -0.01 & 0.98 \\
\hline & & & & right & -1.70 & 0.92 \\
\hline
\end{tabular}

Note-Follow-up $t$ tests corrected for multiple comparisons. $\quad{ }^{*} p<.05 . \quad{ }^{* *} p<.01$.

for other-race in comparison with same-race faces (Ito \& Urland, 2005). Important next steps will be to train participants to recognize monkey faces at the same level of performance as human faces and to examine the electrophysiological differences before, during, and after training. If expertise accounts for this relation, we would predict that one would find (1) a correlation similar to what we found with human faces after training was complete and (2) an increase in the strength of this correlation across time or training intervals. An alternative hypothesis is that, although equating levels of performance across human and monkey faces would lead to no amplitude or latency differences in some ERP components, other components would continue to differ across species. The latter finding would suggest that certain elements of face processing are fundamentally different when one is examining human versus monkey faces, regardless of the facility with which these faces are processed.

Unlike previous studies, the present study found latency differences for the VPP between familiar and unfamiliar faces in that the VPP peaked earlier for the former than for the latter. The N170 is typically insensitive to changes in familiarity (Bentin \& Deouell, 2000; Carmel $\&$ Bentin, 2002). However, in the vast majority of studies of the role of familiarity, participants were not famil- iarized to new faces; instead, highly familiar faces (such as faces of famous people or of friends and family) were used. Recent fMRI work suggests that recognizing highly familiar faces may recruit a different network of structures than does recognizing newly learned faces. More specifically, recognition of highly familiar faces was associated with more widespread activation than was the recognition of newly learned faces (Leveroni et al., 2000). The results of this study suggest that level of familiarity in newly learned (and task-relevant) faces may play an important role in the structural encoding of faces and thus shows up earlier than is typically found when highly familiar faces are used. Effects of familiarity were also found for the N100 component, further suggesting that the familiarity of newly learned faces may be taken into account during the very early stages of face processing. As an alternative, these effects could also be explained by the task-specific demands that were placed on the participants. For example, because the participants were required to indicate whether the current face was the same as or different from the two familiar faces, it is possible that it is this task-specific information, and not the level of familiarity, that is affecting these early components.

A negative component occurring around $300 \mathrm{msec}$ after stimulus onset was found to be most sensitive to 
A Overall Comparison

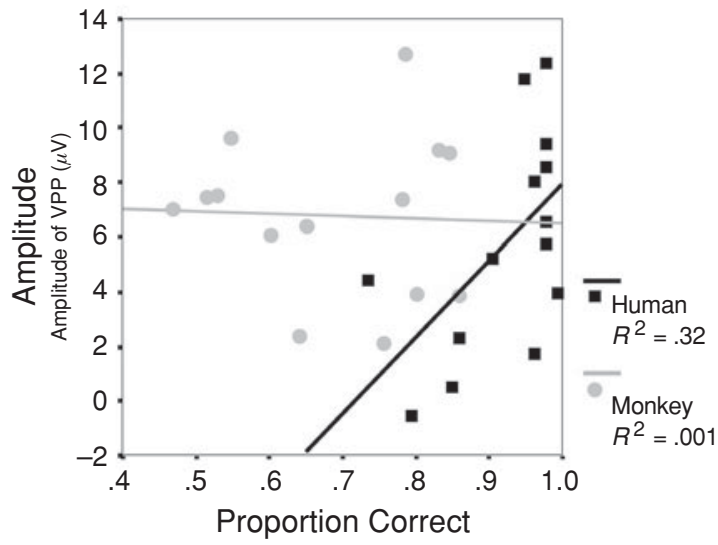

B Familiar Frontal Faces

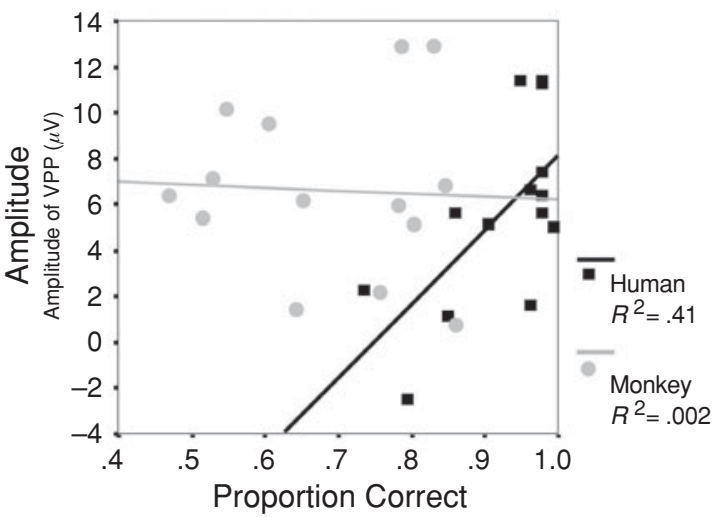

Figure 5. (A) Behavioral measures of proportion correct for the monkey and human tasks (collapsed across conditions) plotted against the maximum amplitude for the VPP component. (B) Behavioral measures of proportion correct for the familiar frontal monkey and human tasks plotted against the maximum amplitude for the VPP component. Responses to monkey faces are shown in gray; responses to human faces are shown in black.

A

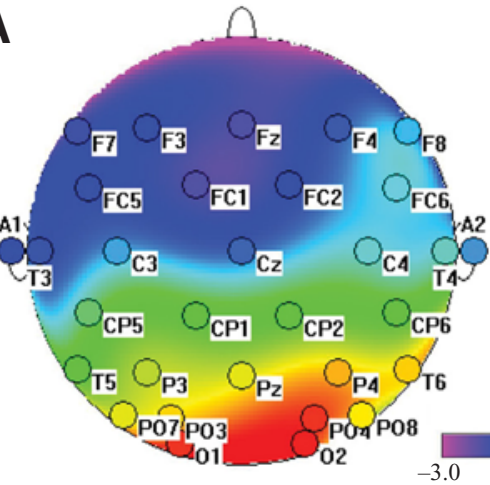

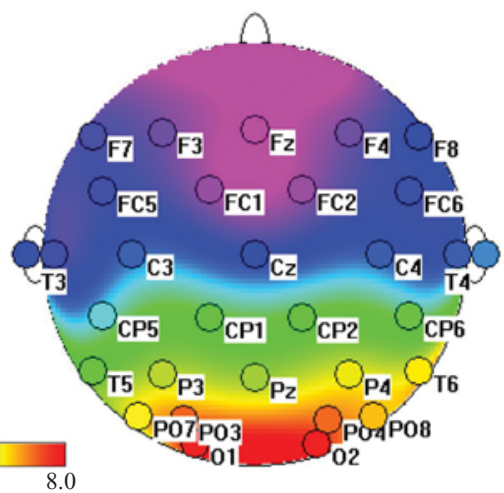

Unfamiliar Faces

\section{Familiar Faces}

B

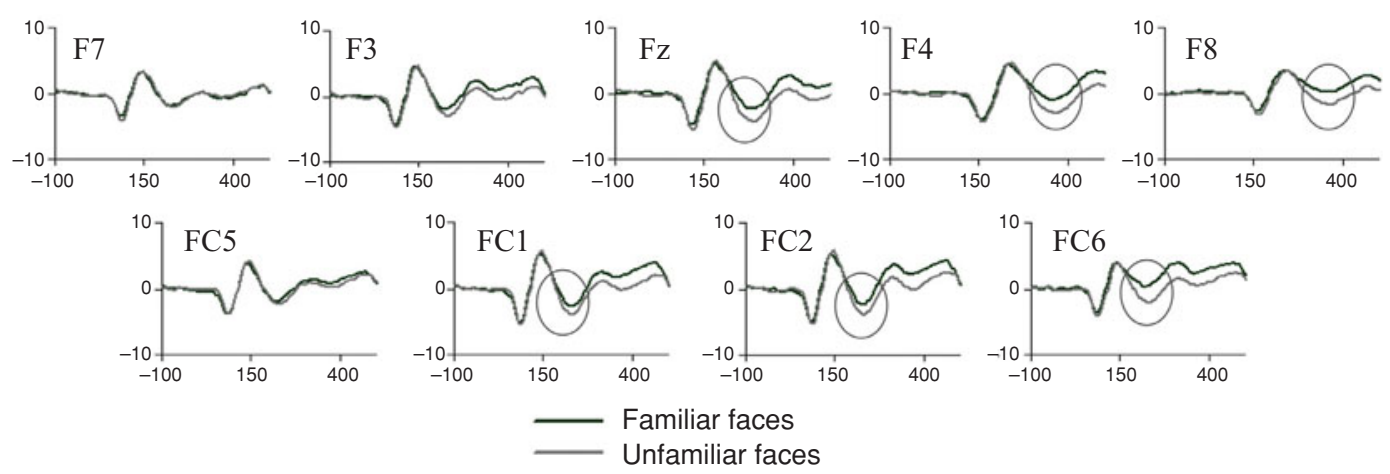

Figure 6. (A) Topographic head plots using a spherical spline interpolation of the ERP response to the familiar (left) and unfamiliar (right) faces in adults for the $\mathrm{N300}$ (stimuli collapsed across species and orientation). (B) Event-related potential grand averages of the response to the familiar human and monkey (black) and unfamiliar human and monkey (gray) faces for frontal leads. Significant amplitude differences are circled for clarity. Each waveform was shifted so that baseline (activity from -100 to 0 ) was equivalent across different conditions and electrodes. 
changes in level of familiarity across species. Across the frontal and central regions of the scalp, unfamiliar faces elicited a greater amplitude response than did familiar faces. In addition, the right hemisphere, but not the left hemisphere, differentiates unfamiliar from familiar faces (see Figure 6). Although these results are consistent with previous reports suggesting that an N300-like component may be modulated by familiarity, the direction of these effects is opposite of what has previously been found. Typically, an N400 analogue to faces is greater in response to famous faces than in response to unfamiliar faces (Bentin \& Deouell, 2000; Eimer, 2000). However, the frontal N400 (or FN400) component is typically greater to new stimuli in comparison with old stimuli in study-test designs with words and pictures (see, e.g., Curran, 2000; Curran \& Cleary, 2003). The design of the present investigation was more similar to the study-test designs used in previous FN400 studies than to the famous/ nonfamous designs used in studies in which a more parietal N400 was found. Thus, the frontal distribution of the N300 and the larger amplitude response to unfamiliar in comparison with familiar faces suggest that recognition of newly learned faces elicits a different pattern of neural activity than does recognition of famous or previously familiar faces. Future investigations should explore the different levels and kinds of face familiarity and their effects on the components reported on above.

To summarize, the results of the present study indicate electrophysiological differences across changes in species, orientation, and familiarity. Furthermore, the electrophysiological data converge with the behavioral findings in a number of ways, supporting the hypothesis that previous experience with certain categories of faces influences the specificity of the face processing system. Importantly, human face experience does not aid in the recognition of other categories of faces.

\section{REFERENCES}

Barrett, S. E., Rugg, M. E., \& Perrett, D. I. (1988). Event-related potentials and the matching of familiar and unfamiliar faces. Neuropsychologia, 26, 105-117.

Bentin, S., Allison, T., Puce, A., Perez, E., \& McCarthy, G. (1996) Electrophysiological studies of face perception in humans. Journal of Cognitive Neuroscience, 8, 551-565.

Bentin, S., \& Deouell, L. Y. (2000). Structural encoding and identification in face processing: ERP evidence for separate mechanisms. Cognitive Neuropsychology, 17, 35-54.

Bertrand, O., Perrin, F., \& Pernier, J. (1985). A theoretical justification of the average reference in topographic evoked potential studies. Electroencephalography \& Clinical Neurophysiology, 62, 462-464.

BöTZEL, K., \& GRÜSSER, O.-J. (1989). Electric brain potentials evoked by pictures of faces and non-faces: A search for "face-specific" EEG potentials. Experimental Brain Research, 77, 349-360.

Carmel, D., \& Bentin, S. (2002). Domain specificity versus expertise: Factors influencing distinct processing of faces. Cognition, 83, 1-29.

Curran, T. (2000). Brain potentials of recollection and familiarity. Memory \& Cognition, 28, 923-938.

Curran, T., \& Cleary, A. M. (2003). Using ERPs to dissociate recollection from familiarity in picture recognition. Cognitive Brain Research, 15, 191-205.

Damasio, A. R., Damasio, H., \& Van Hoesen, G. W. (1982). Prosopag- nosia: Anatomic basis and behavioral mechanisms. Neurology, 32 331-341.

de Haan, M., Pascalis, O., \& Johnson, M. H. (2002). Specialization of neural mechanisms underlying face recognition in human infants. Journal of Cognitive Neuroscience, 14, 199-209.

De RenZI, E. (1986). Current issues in prosopagnosia. In H. D. Ellis, M. D. Jeeves, F. Newcombe, \& A. Young (Eds.), Aspects of face processing (pp. 243-252). Dordrecht: Nijhoff.

DIEN, J. (1998). Issues in the application of the average reference: Review, critiques, and recommendations. Behavior Research Methods, Instruments, \& Computers, 30, 34-43.

EIMER, M. (2000). Event-related brain potentials distinguish processing stages involved in face perception and recognition. Clinical Neurophysiology, 111, 694-705.

FARAH, M. J. (1996). Is face recognition "special"? Evidence from neuropsychology. Behavioral Brain Research, 76, 181-189.

Gauthier, I., Behrmann, M., \& Tarr, M. J. (1999). Can face recognition really be dissociated from object recognition? Journal of Cognitive Neuroscience, 11, 349-370.

Gauthier, I., Curran, T., Curby, K. M., \& Collins, D. (2003). Perceptual interference supports a non-modular account of face processing. Nature Neuroscience, 6, 428-432.

Gauthier, I., Skudlarski, P., Gore, J. C., \& Anderson, A. W. (2000). Expertise for cars and birds recruits brain areas involved in face recognition. Nature Neuroscience, 3, 191-197.

Gauthier, I., Tarr, M. J., Anderson, A. W., Skudlarski, P., \& Gore, J. C. (1999). Activation of the middle fusiform "face area" increases with expertise in recognizing novel objects. Nature Neuroscience, 2 , 568-573.

Gratton, G., Coles, M. G. H., \& Donchin, E. (1983). A new method for off-line removal of ocular artifact. Electroencephalography \& Clinical Neurophysiology, 55, 468-484.

Gross, C. G., Bender, D. B., \& Rocha-Miranda, C. E. (1969). Visual receptive fields of neurons in inferotemporal cortex of the monkey. Science, 166, 1303-1306.

Gross, C. G., Rocha-Miranda, C. E., \& Bender, D. B. (1972). Visual properties of neurons in inferotemporal cortex of the macaque. Journal of Neurophysiology, 35, 96-111.

Hillyard, S. A. (1981). Selective auditory attention and early eventrelated potentials: A rejoinder. Canadian Journal of Psychology, 35, 159-174.

Ito, T. A., \& URLAND, G. R. (2005). The influence of processing objectives on the perception of faces: An ERP study of race and gender perception. Cognitive, Affective, \& Behavioral Neuroscience, 5, 2136.

JEFFREYS, D. A. (1989). A face-responsive potential recorded from the human scalp. Experimental Brain Research, 78, 193-202.

JEFFREYS, D. A. (1996). Evoked potential studies of face and object processing. Visual Cognition, 3, 1-38.

Jeffreys, D. A., \& Tukmachi, E. S. A. (1992). The vertex-positive scalp potential evoked by faces and by objects. Experimental Brain Research, 91, 340-350.

Jeffreys, D. A., Tukmachi, E. S. A., \& Rockley, G. (1992). Evoked potential evidence for human brain mechanisms that respond to single, fixated faces. Experimental Brain Research, 91, 351-362.

Joyce, C., \& Rossion, B. (2005). The face-sensitive N170 and VPP components manifest the same brain processes: The effect of reference electrode site. Clinical Neurophysiology, 116, 2613-2631.

Kanwisher, N., McDermott, J., \& Chun, M. M. (1997). The fusiform face area: A module in human extrastriate cortex specialized for face perception. Journal of Neuroscience, 17, 4302-4311.

Leveroni, C. L., Seidenberg, M., Mayer, A. R., Mead, L. A., Binder, J. R., \& RAO, S. M. (2000). Neural systems underlying the recognition of familiar and newly learned faces. Journal of Neuroscience, $\mathbf{2 0}$, 878-886.

Perrett, D. I., Mistlin, A. J., \& Chitty, A. J. (1987). Visual neurones responsive to faces. Trends in Neurosciences, 10, 358-364.

Perrett, D. I., Rolls, E. T., \& CAan, W. (1982). Visual neurons responsive to faces in the monkey temporal cortex. Experimental Brain Research, 47, 329-342. 
Picton, T. W., Bentin, S., Berg, P., Donchin, E., Hillyard, S. A., JOHNSON, R., JR., ET AL. (2000). Guidelines for using human eventrelated potentials to study cognition: Recording standards and publication criteria. Psychophysiology, 37, 127-152.

Rossion, B., Delvenne, J. F., Debatisse, D., Goffaux, V., Bruyer, R., Crommelinck, M., \& Guerit, J. M. (1999). Spatio-temporal localization of the face inversion effect: An event-related potentials study. Biological Psychology, 50, 173-189.

Rossion, B., Dricot, L., Devolder, A., Bodart, J.-M., CromMelinck, M., De Gelder, B., \& ZoontJes, R. (2000). Hemispheric asymmetries for whole-based and part-based face processing in the human fusiform gyrus. Journal of Cognitive Neuroscience, 12, 793-802.

Rossion, B., Joyce, C. A., Cottrell, G. W., \& Tarr, M. J. (2003). Early lateralization and orientation tuning for face, word, and object processing in the visual cortex. NeuroImage, 20, 1609-1624.

Sagiv, N., \& Bentin, S. (2001). Structural encoding of human and schematic faces: Holistic and part-based processes. Journal of Cognitive Neuroscience, 13, 937-951.

\section{NOTES}

1. Dipoles arise from synchronous activity of populations of neurons within the brain. This activity results in a signal with a positive end and a negative end and can be recorded on the surface of the scalp.

2 . In the present experiment, data were also rereferenced to the average reference to determine whether similar effects were found for the VPP and the N170. However, because of insufficient spatial sampling over the scalp, we did not have enough power to detect significant differences across conditions for the N170. Nevertheless, it is important to note that the patterns of results (although marginal or nonsignificant for the N170) were similar across both components.

(Manuscript received October 27, 2004; revision accepted for publication August 25, 2005.) 